\title{
A multiscale finite element model of sliding wear for cobalt-chromium undergoing ratcheting wear
}

\author{
P.S.G. Cross $^{*}$, G. Limbert ${ }^{1,2}$, D. Stewart ${ }^{3}$, R.J.K. Wood ${ }^{1}$ \\ ${ }^{1}$ University of Southampton, Southampton, Hampshire, UK \\ ${ }^{2}$ University of Cape Town, South Africa \\ ${ }^{3}$ Rolls-Royce plc., Derby, UK
}

\begin{abstract}
Cobalt-chromium alloys are used in reciprocated sliding wear applications where the mated surfaces cannot be lubricated, due to their excellent frictional properties and ability to resist seizure. However, various health risks due to cobalt wear particle generation motivate the replacement of cobalt-based systems. It is suggested that a numerical model of reciprocated dry sliding wear for cobalt-chromium alloys would aid in the development of cobalt-free alternatives to remove any health risks. Therefore, this work focuses on building a mechanistic, i.e. determined purely through physical terms, numerical model of dry reciprocated sliding wear for a specific cobalt-chromium alloy, informed by the experimental literature, to gain an understanding of cobalt wear-rates in response to the tribological loading conditions. A multi-scale method is employed, where the wear is determined by a microscale model of wear, which simulates wear after the material is brought up to a critical strain to failure and material rupture occurs, and the microscale wear-rates are homogenised to the macroscale by use of a statistic model of rough contact. This improves over previous methods by allowing one to observe how material wear-rates are controlled by changes in the elasto-plastic material parameters and geometry of an engineering component. The current numerical model predicts the correct scale of wear, in the range of $1 \times 10^{-14} \mathrm{~m}^{3} / \mathrm{Nm}$ or $1 \times 10^{-5} \mathrm{~mm}^{3} / \mathrm{Nm}$, typical for the chosen alloy under dry sliding conditions and is validated against experimental data. The model allows for further development, such as the incorporation of frictional heating, microscale heterogeneity, or the evolution of surface roughness parameters during wear.
\end{abstract}

Keywords: Cobalt-chromium, Reciprocated sliding, Ratcheting wear, Multiscale modelling, Homogenisation

\section{Introduction}

Cobalt-chromium (Co-Cr) alloys are used throughout industry where it is not possible to lubricate the sliding contact interface. Here it is used due to its relative wear resistance and beneficial frictional properties, when compared to other materials [1]. Particularly, it is used within the rock drilling, medical, and nuclear industry due to its excellent friction performance during reciprocated dry sliding motion preventing galling, a severe type of adhesive wear which can result in the seizure of components that should otherwise undergo relative reciprocated sliding motion.

Wear from these cobalt-chromium components nevertheless cause various health risks $[2,3]$, so there is motivation to replace cobalt-based alloys, particularly with iron-based substitutes [4]. However, there is yet to be a suitable replacement and as such, there is great motivation to seek an understanding of how these materials wear during dry reciprocated motion in order to aid the replacement of cobalt-based alloys. The aim of this work is then to build a mechanistic - i.e. determined through purely physical terms - finite element model of reciprocated sliding wear for a hot isostatically pressed (HIPed) form of a cobalt-chromium alloy, as informed by the present experimental work available in the literature. Particularly HIPed is 
of interest due to its beneficial wear properties [5]. This seeks to build on other models of wear that use the Archard equation of wear [6], given as:

$$
W_{v}=k N s
$$

where $W_{v}$ is total wear volume, $N$ is the experimental load, $s$ is the sliding distance, and $k$ is a 'wear constant'. The Archard equation prevents one from being able to make predictions on material wear-rates as a function of material properties, as it is not clear what $k$ represents, thus severely limiting its usefulness in designing material alternatives. In addition to this, this equation suggests that wear is a linear function of load, which is not necessarily case for cobalt-chromium alloys [7]. Given the inappropriateness of Archard's equation, another wear model must be found.

By observing the wear mechanisms detailed throughout the wear literature for cobalt-chromium alloys, it is possible to determine an alternative wear model. In the work by Cross et al. [8], evidence of plate-like wear was seen for a load and speed range of $160 \mathrm{~N}$ to $1000 \mathrm{~N}$ and $0.02 \mathrm{~m} / \mathrm{s}$ and $0.05 \mathrm{~m} / \mathrm{s}$ respectively under self-mated reciprocated sliding conditions. Similar wear was also observed for laser-clad cobalt-chromium materials in the literature $[9,10,11]$. This type of wear led to lamellar wear particles, which formed due to material rupture propagating in the sub-surface. Such lamellar wear debris is seen throughout the literature $[9,10,11]$, particularly on rail steels where ratcheting deformation, ie incremental unidirectional plastic straining, is known to occur [12]. Particularly, material rupture propagated on planes that suppress elastic fracture [13], and so this type of wear is likely to be mediated by plastic deformation. In additional, plastic shear strains above $1000 \%$ were seen near the subsurface in the literature, and on the pin edge [14].

The various wear mechanisms, such as lamellar wear particles and high strains, can be explained by the ratcheting model of wear by Kapoor et al. [15]. Ratcheting is a type of material deformation, which occurs when the material is cyclically loaded above a critical 'shakedown' limit [16], after which it undergoes unidirectional incremental strain accumulation up until material failure. With each loading cycle, as would be expected for a microscopic asperity coming in and out of contact during reciprocated sliding motion, the material progressively strains along a single primary direction until it accumulates enough strain to rupture and fail [13]. This incremental straining would explain why the material can exceed strains of up to $1000 \%$, as seen in the work of Cabrol et al. [14], while the high hydrostatic pressure explains the ability for the material to suppress failure [17]. In addition, analytical studies of material deformation with a ratcheting model explains the existence of lamellar wear debris [15] and the highly deformed nature of the wear-interface $[18,19]$.

A numerical model of ratcheting wear, titled the Franklin-Kapoor model hitherto called the tribological layers model, can describe ratcheting wear for a simplistic Hertzian geometry [20], i.e. a single asperity, and may begin to explain the wear-rates of cobalt-chromium. To overcome the restriction to only Hertzian contacts, and apply the FranklinKapoor model to more general macroscopic contacts, an homogenisation scheme is used to relate the microscale wear to a finite element in a macroscale model of wear. The Franklin Kapoor model will now be introduced, and the methodology behind the homogenisation scheme will be given in the next section.

\subsection{Ratcheting wear model}

As co-cr appear to be undergoing ratcheting wear under high load dry sliding conditions [8], the Franklin-Kapoor model of wear is used [20]. Typically this is used for spherical or cylindrical geometries larger than several millimetres, however this paper simply adapts the model to the microscale by applying it to cylinders with radii of about $1.5 \mu \mathrm{m}$, similar to the asperity tips for this material.

Primarily, the model uses an elastic half-space, divided up into layered elements, each of which track the amount of plastic shear strain accumulation can be calculated using the equation:

$$
\Delta \gamma_{i+1}= \begin{cases}c \frac{\tau_{x y}}{\kappa\left(\gamma_{i}\right)}, & \text { if } \tau_{x y}>k . \\ 0, & \text { otherwise. }\end{cases}
$$

where $c$ is the strain-accumulation per cycle, to be determined from experiment, and $\tau_{x y}$ and $\kappa(\gamma)$ are the shear stress distribution under the point of contact and shear strength function respectively. Here, the shear strength is a function of the current value of accumulated shear strain at that point in the material as to simulate material hardening. If the shear stress does not exceed the shear strength, $k$, then there will be no accumulation of shear strain and the material response will be purely elastic. 
The full derivation of this equation can be found in ref. [21] and ref. [22].

In particular, shear strain is focused on, as the subsurface cracks leading to the removal of layers propagate parallel and in the direction of sliding. When critical shear is reached in a given layer, it is removed along with all the layers above it, as to give wear depth. The numerical wear algorithm used in the Franklin-Kapoor model of wear is outlined in Figure 1.

For this analysis, the asperity is assumed to be cylindrical plane-strain, as justified by the lapping procedure resulting in a prominent surface lay [13].

In the case of hot isostically pressed (HIPed) cocr, through the authors' own work performing uniaxial tension tests using test standard ISO 68921, it was demonstrated that HIPed co-cr could be modelled using a Voce-like hardening curve [23]. The function that represents this hardening is given as:

$$
\kappa(\gamma)=\frac{\sigma_{Y}}{\sqrt{3}}+\frac{H}{\sqrt{3}}\left(1-e^{-b \gamma}\right)
$$

where $\sigma_{Y}$ is the yield stress, $H$ is the saturation stress, and $b$ is the hardening rate. The factor of $1 / \sqrt{3}$ here relates the values of yield stress and saturation stress their shear counterparts. 5 repeats were performed and a yield stress, saturation stress, and hardening rate of $450 \mathrm{MPa}, 1050 \mathrm{MPa}$, and 200 were discovered respectively.

From equation 2 and 3, we can see that the ratcheting model requires knowledge of the parameter $c$, the plastic shear strain accumulated with each cycle of an asperity and the hardness at the wear interface. Furthermore, in order for the sliding contact to exceed yield and lead to the scale of plastic deformation seen in experiment $[8,14,24]$, the real pressure due to surface roughness must be accounted for. The methodologies for acquiring these parameters are given in the next sections.

\section{Methodology}

\subsection{Tribological testing}

A description of the tribological tests can be found in the work of Cross et al. [8], but are provided here for convenience.

The wear tests were conducted under laboratory conditions at room temperature. The geometry consisted of a flat cylindrical pin, of diameters between $8 \mathrm{~mm}$ and $10 \mathrm{~mm}$, sliding back and forth in a reciprocating motion on a flat plate under dry conditions. The surfaces were lapped to a surface roughness of $0.1 \mu \mathrm{m} \mathrm{Ra}$ as to replicate the in-service conditions of a given application.

The wear tests were separated into a high load condition and low load condition which ran for a total sliding distance of $100 \mathrm{~m}$ and $500 \mathrm{~m}$, corresponding to a reciprocating stroke length of $10 \mathrm{~mm}$ and $25 \mathrm{~mm}$, respectively. This resulted in a total cycle number of 5000 and 10000 for each distance.

The high load condition used a pin of diameter $8 \mathrm{~mm}$, sliding at a speed of $0.02 \mathrm{~m} / \mathrm{s}$ under loads of $600 \mathrm{~N}, 700 \mathrm{~N}, 800 \mathrm{~N}, 900 \mathrm{~N}$ and $1000 \mathrm{~N}$. The low load condition was slid at a speed of $0.05 \mathrm{~m} / \mathrm{s}$ under loads of $40 \mathrm{~N}, 160 \mathrm{~N}, 240 \mathrm{~N}, 320 \mathrm{~N}$, and 400 $\mathrm{N}$. These loading conditions were chosen such that any wear transitions under load could be observed, with the high load parameters replicating in-service loading conditions. Particularly, low speeds of 0.02 and $0.05 \mathrm{~m} / \mathrm{s}$ were chosen as to reduce friction heating influence.

\subsection{Nano-indentation and micro hardness}

Nano-indentation was performed on a NanoTest Vantage (MicroMaterials, Wrexham, UK). A diamond Berkovich indenter was used, with Young's modulus and Poisson's ratio of $1141 \mathrm{GPa}$ and 0.07 respectively. Over 400 indents were performed, in a 20 by 20 grid from the contact interface into the bulk.

Additional micro hardness indentation was performed using a Vickers diamond indenter. The chosen load for indentation was $50 \mathrm{kgf}$ for $15 \mathrm{sec}-$ onds. For each test, the pins after the test were cross-sectioned, and indented away from the wearinterface to a total distance of 600 microns. An average of 3 repeats were taken for the pin.

\subsection{Strain analysis}

Given the importance of plastic strain in the ratcheting wear model, the worn pins from the research of Cross et al. [8] were mounted and crosssectioned along the sliding axis to observe any subsurface strain. To quantify plastic shear strain, the equation derived by Dautzenberg [25], applicable up to large strains, was used:

$$
\gamma_{x y}=\tan (\theta)
$$

where $\theta$ is the angle that the deformed material makes with the normal to the wear interface, some 30 microns from the surface, as shown in Figure 


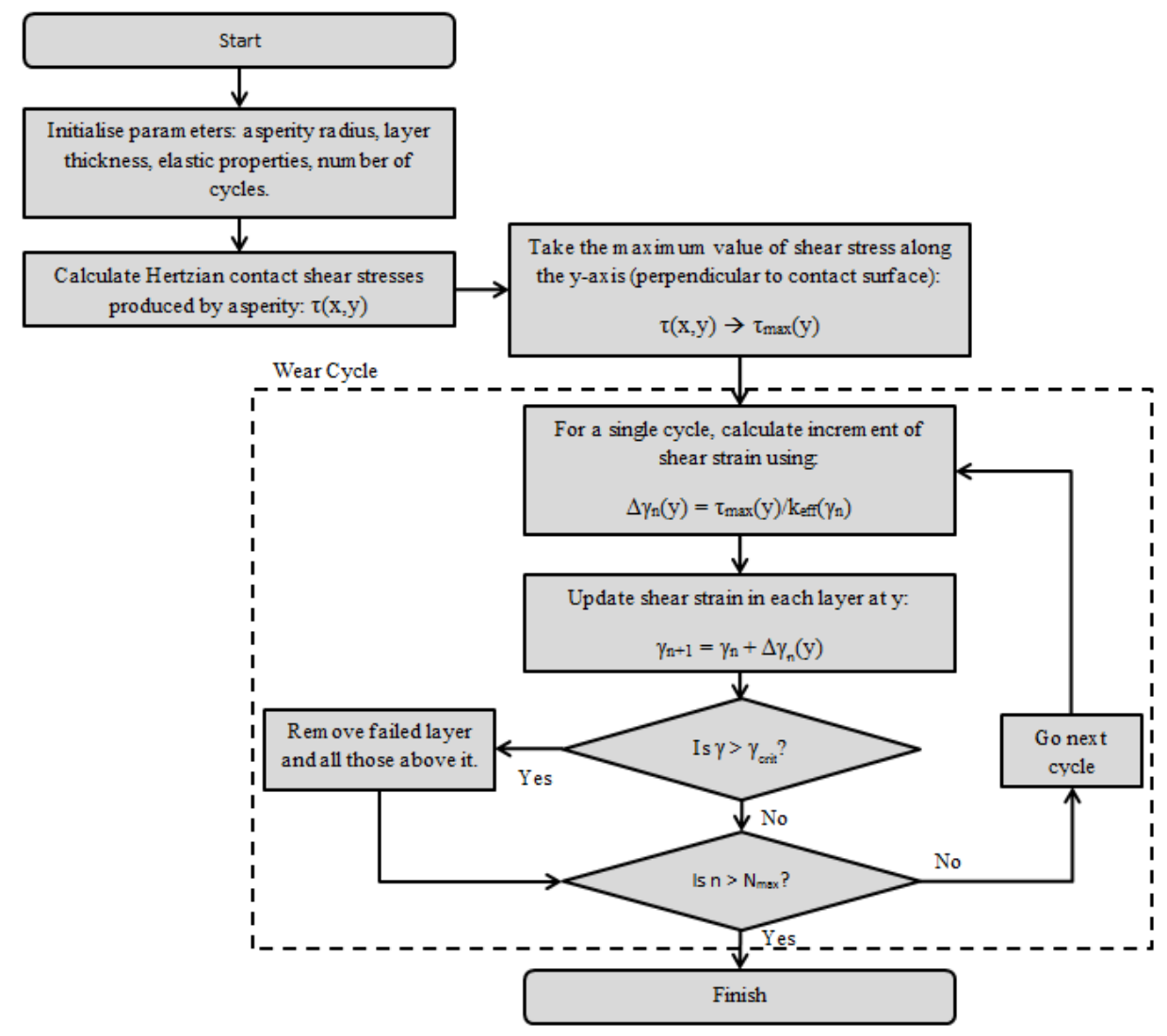

Figure 1: Schematic showing how the Franklin-Kapoor wear model works in MATLAB.

2. This analysis holds for a perfectly plastic rigid material undergoing finite deformations in simple shear, which has been used by Cabrol et al. [14] and Kapoor et al. [26] to determine the tribological strain-to-failure for HIPed co-cr and pearlitic steels respectively.

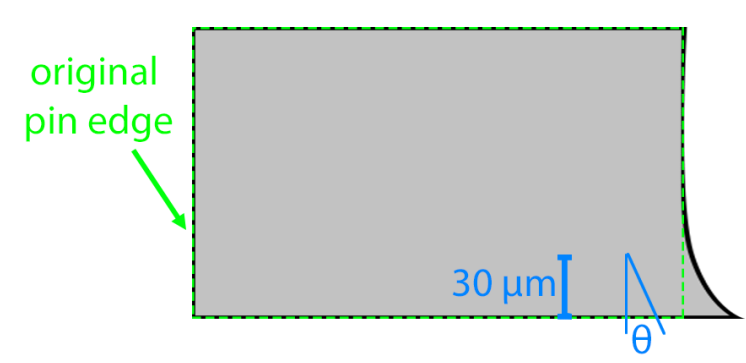

Figure 2: Schematic showing the angle measuring method employed on the strained pins.

In the Franklin-Kapoor wear model [20], we are interested in the plastic strain per cycle, $c$. This is found by calculating the linear equation given by
Tyfour et al. [22]:

$$
c=\frac{\gamma_{x y}}{\left(p_{0} / k_{e f f}-p_{r}\right) N}
$$

where $\gamma_{x y}$ is the maximum plastic shear strain after sliding, $p_{0}$ is the mean contact pressure calculated from profilometry data, $k_{e f f}$ is the shear strength of the interface after a sliding wear test calculated using $k_{e f f}=k\left(H_{f} / H_{i}\right)$ where $k=\sigma_{Y} / \sqrt{3}$ and $H_{f}$ and $H_{i}$ are the final and initial values of hardness at the wear interface. The value $N$ is the number of sliding cycles, and $p_{r}$ is the threshold of contact pressure required to make the material undergo ratchet deformation. This can be calculated by using the shakedown map for repeated rolling/sliding contact as given by Johnson [13], and simply determining the value $p_{0} / k$ corresponding to the coefficient of friction $\mu$ seen in experiment.

Wear is expected to occur when the material strains above a critical strain to failure. Due to the lack of experimental data on this, the critical strain to failure was taken as the maximum strain 
seen at the edge of the pin.

\subsection{Profilometry and pressure analysis}

To acquire the values of mean pressure, $p_{0}$, the surface profile before and after the tribology experiment was measured using a Talysurf profilometer (Taylor Hobson, Leicester, UK) for every test conducted in ref. [8]. As the ratcheting model is dependant on asperity radius, as well as the height distribution function, the mean radius was calculated from the profile data using the mean radius of curvature equation:

$$
R=\left|\frac{\left(1+z^{\prime 2}\right)^{3 / 2}}{z^{\prime \prime}}\right|
$$

where $\mathrm{z}$ is the surface roughness data, i.e. the profile minus it's form.

To calculate the mean pressure, i.e. the load carried by the real area of contact from asperities, such that the load carried matches the normal load used in experiment, $N_{\exp }$, the GreenwoodWilliamson model [27] of rough contact in used in conjunction with a straight-forward computational methodology. Albeit for elastic contacts only, such a method is justified due to the ratcheting threshold [13] and plastic shear strain accumulation function (equation 5) being determined through a purely elastic analysis. The equation that represents the Greenwood-Williamson model is given as:

$$
F=A_{c} \int_{d}^{\infty} \phi(z) d F(z-d) d z
$$

where $A_{c}$ is the asperity number across the contact interface, $d$ is the separation between surfaces, $\phi(z)$ is a Gaussian height distribution of asperities, and $d F$ is the microscale quantity we wish to homogenise to the overall quantity $F$. The distribution, $\phi(z)$, can be determined by fitting a probability distribution function to the surface roughness height data. Figure 3 shows a schematic representation of these qualities.

To determine the microscopic load, $d F$, a Hertzian cylinder-on-flat contact model was used. A cylindrical asperity geometry was chosen due to the lapping process giving a prominent surface lay consisting of almost-unidirectional parallel lines [28]. The relation that gives force per cylindrical asperity, $d F$, as a function of the indentation depth or penetration, $\delta$, is

$$
d F / L \simeq \pi R E^{*} 0.31\left(\frac{\delta}{R}\right)^{1.28}
$$

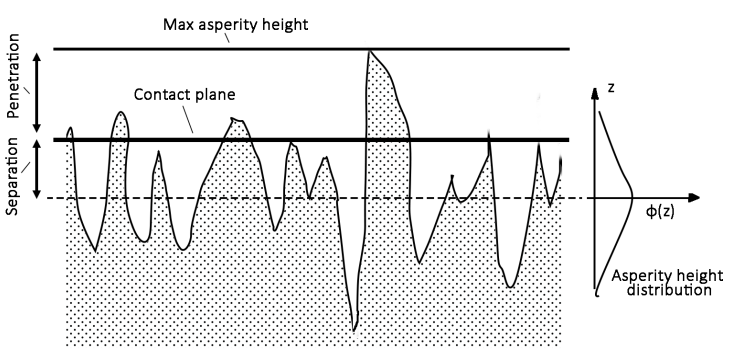

Figure 3: A schematic showing the parameters used in the Greenwood-Williamson model of rough contact. Here $d$ is the separation between surfaces and $\phi(z)$ is a distribution function of the asperity heights.

where $E^{*}$ is the reduced modulus [28], $L$ is the out-of-plane cylinder length. Derivation of this equation is given in appendix 5.1. Substituting 8 into 7 , in order to homogenise the contact force (a more mathematically rigorous means to reach the following equation is given in ref [27]), gives:

$$
F / L \simeq \pi R A_{c} E^{*} 0.31 \int_{d}^{\infty} \psi(z)\left(\frac{z-d}{R}\right)^{1.28} d z
$$

and

$$
A_{r} / L=2 R^{\frac{1}{2}} A_{c} \int_{d}^{\infty} \psi(z)(z-d)^{\frac{1}{2}} d z
$$

where $d$ is the separation between surfaces, $A_{c}$ are the number of asperities on the surface, $L$ is the contact length, and $\psi(z)$ is the asperity height distribution. $\delta$ can be expressed in terms of the separation by $(z-d)$. With equation 9 , it is now possible to search for a separation, $d$, so that:

There exists $d$, such that $\Pi=N_{\exp }-F \rightarrow 0$

where $N_{\text {exp }}$ is the experimental normal load used in the tribology experiment. The true pressure, $p_{0}=F / A_{r}$, can be found by inputting the separation into equation 10 to get $A_{r}$. This value of $p_{0}$ can then be used to find the shear stress distribution, $\tau_{x y}$, under the point of contact by assuming the true pressure is distributed uniformly across a material element. The value of $\tau_{x y}$ can then used in equation 2 to calculate the material loss due to ratcheting for this given pressure. 


\subsection{Finite element model of wear}

In order to homogenise the microscale wear, given by the Franklin-Kapoor ratcheting model [20], to a macroscopic wear-rate a finite element contact solution of the macro-scale geometry was combined with the aforementioned true pressure computational methodology. In this way, a stress-field pertaining to microscale roughness, under the point of contact, could then be used as input into a FranklinKapoor wear model. This allows wear to be simulated in mechanistic terms, by observing how material is strained and ruptured due to the mean pressures generated by a rough surface leading to wear particle generation.

A finite element model of wear was built in Comsol Multiphysics with pre- and post- processing handled by Livelink for Matlab. The elements used in the finite element geometry were quadratic serendipity triangular elements. The simulation geometry and boundary conditions can be seen in Figure 4.

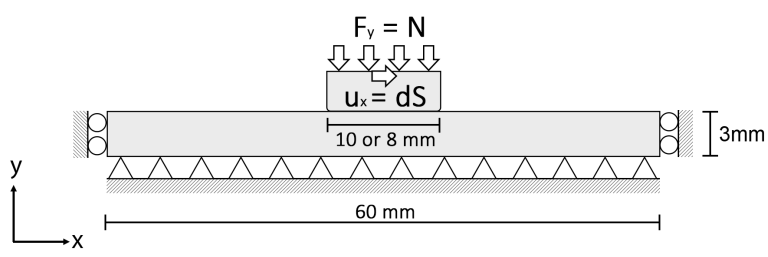

Figure 4: The boundary conditions and geometry used in the macroscopic finite element model of wear with a ratcheting subroutine.

First, a plane-strain finite element model of contact for the macro-scale geometry used in experiments was built. The finite element mesh at the contact boundary was chosen to be uniform in element size. This simplified the wear model, as for elements of varying size at the wear boundary it is necessary to interpolate the wear data onto a uniform grid [29]. The finite element contact problem for the macroscale smooth geometry was then solved for a given desired load in order to give the distribution over pressure across the contact. The pressure at each node, $p_{n}$, where $n$ represents the specific node, was then multiplied by the width of the element boundary at the mating interface, $w_{n}$, in order to give the load density distribution at that specific node, $F_{n} / L=w_{n} p_{n}$, across the contact interface. The equation that represents this procedure is given as:

$$
\frac{F_{n}}{L}=\frac{w_{n}\left(A_{c} / L\right)}{L} \int_{d_{n}}^{\infty} \phi(z) d F_{n}\left(z-d_{n}\right) d z
$$

Then, for each node, the separation between the pin and plate surfaces at a specific node can be calculated using the methodology outlined section 2.4 using the condition shown in equation 11 by searching for the separation that gives the correct force at a given node.

An example of the results of this procedure can be seen in Figure 5 for a macroscopic load of $40 \mathrm{~N}$ applied over a boundary of $8 \mathrm{~mm}$. Importantly, the pressure values given here exceed a value of $60 \mathrm{MPa}$, whereas for the test geometry in ref. [8] of a pin with diameter $10 \mathrm{~mm}$ the maximum pressure only reaches $0.5 \mathrm{MPa}$, thus highlighting how different the pressure profiles may be when one accounts for surface roughness in the analysis.

With the separation-per-node found, the wearrate could be determined. The shear stress field in the half-space, $\tau_{x y}$, was then acquired by calculating the mean pressure at a given node by substituting the separation at each node, $d_{n}$, into equation 10 for real area. The mean pressure at this node can then be calculated via $p_{0, n}=F_{n} / A_{r, n}$ where $F_{n}$ is the force carried at this node. Assuming this mean pressure is distributed uniformly across a given element, the shear stress can be calculated using the equations of ref. [28]. For normal loading of a uniform pressure distribution, where $z$ is the depth from the contact interface:

$$
\sigma_{x y, N}=-\frac{p_{0} 2 z^{2}}{\pi} \int_{-w_{n} / 2}^{w_{n} / 2} \frac{(x-s)}{\left[(x-s)^{2}+z^{2}\right]^{2}} d s
$$

and shear loading, normally due to sliding friction forces given by $\mu p 0$, where $\mu$ is the frictional coefficient:

$$
\sigma_{x y, S}=-\frac{\mu p_{0} 2 z}{\pi} \int_{-w_{n} / 2}^{w_{n} / 2} \frac{(x-s)^{2}}{\left[(x-s)^{2}+z^{2}\right]^{2}} d s
$$

which when superimposed give the shear stress solution for an elastic body being deformed by a normally loaded contact, sliding with a frictional coefficient, $\mu$ : 
(a)

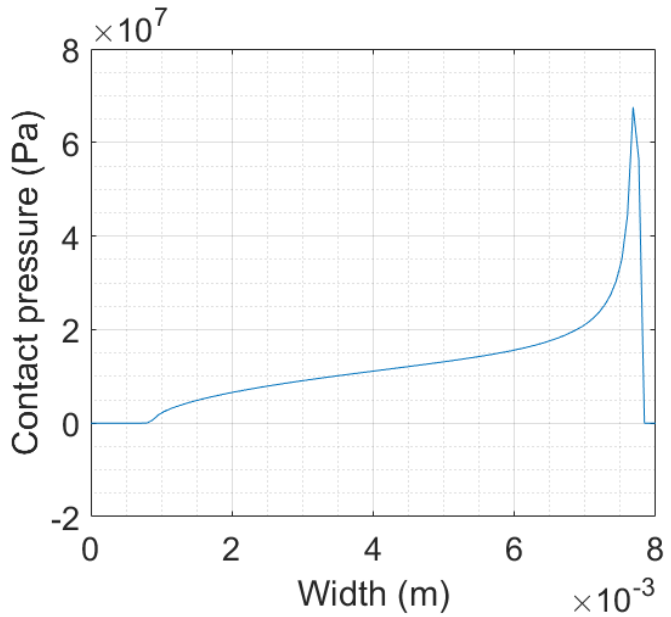

(b)

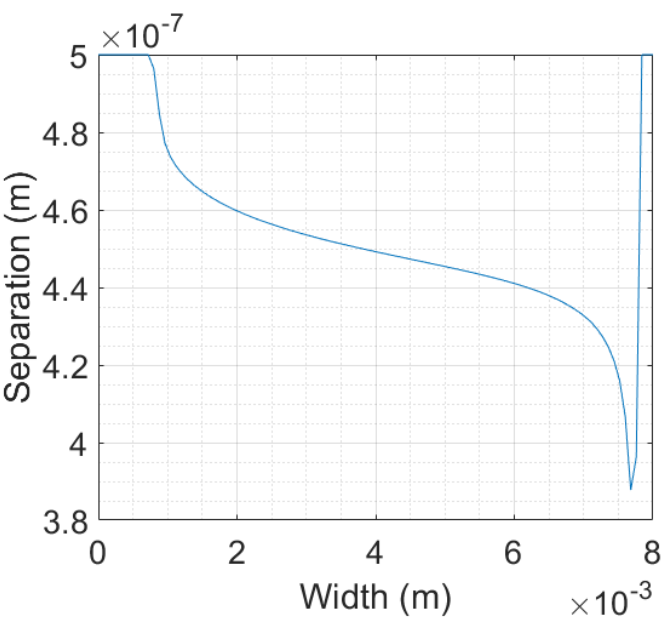

Figure 5: (a) The typical contact pressure across the wear interface solved in the FEA (b) The separation calculated from the pressure for each surface node using the GreenwoodWilliamson model.

$$
\tau_{x y}=\sigma_{x y, N}+\sigma_{x y, S}
$$

Finally, we are only concerned with the maximum value of shear stress as a function of depth, as this will cause material straining and rupture. The maximum value of $\tau_{x y}$ may then be used in equation 2 to acquire the strain at a given node. Once this strain exceeds a critical strain to failure, the tribological layer at node $n$ will be removed to give a corresponding wear-depth of $h_{n}$. An example of the stress field in the pin is shown in Figure 6.

The standard approach to simulating wear using finite elements is to use the pressure distribution calculated from the macroscale geometry, in combination with a given wear subroutine. This subroutine is typically a modified form of the Archard

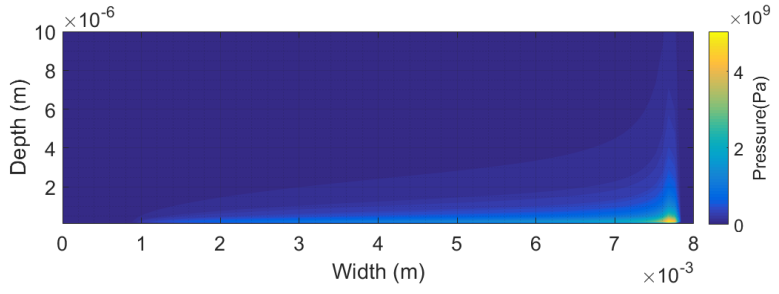

Figure 6: The Hertzian stress field under the point of contact using the homogenisation procedure. Note how the stress predicted using this procedure gives a much higher stress, capable of yielding the material, when compared to the pressure calculated from the apparent area.

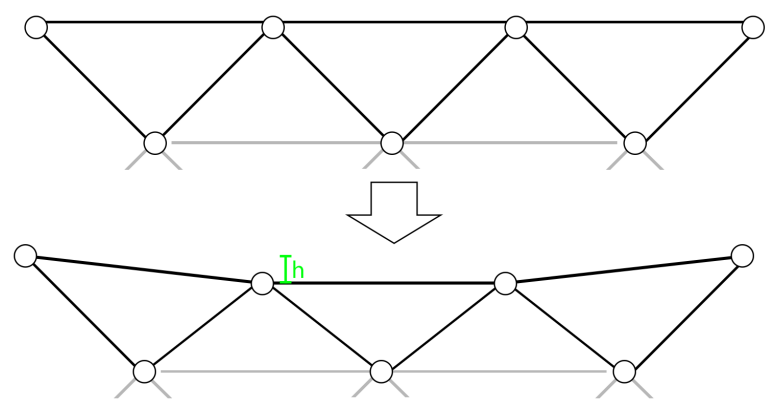

Figure 7: A schematic demonstrating how the finite element nodes are adjusted in response to a wear depth, $h$, determined using a degradation function and contact pressure.

equation, which describes wear depth in terms of pressure and velocity [29]. The wear depth per node, $h_{n}$, is calculated with each increment of sliding distance, $d s$, and then used to adjust the finite element geometry as shown in Figure 7 over the course of a simulation. In the case of the ratcheting subroutine, the wear depth, $h_{n}$ is calculated from the height of the layer that is removed when the strain at a given node exceeds a critical strain to failure. The wear-rate can then be found at the end of the simulation by conducting an Archardlike analysis, by taking the wear volume, $W_{v}$ and dividing it by the sliding distance and load.

Each simulation run was done to recreate each experiment from ref. [8]. For a speed of $0.05 \mathrm{~m} / \mathrm{s}$, a contact length of $10 \mathrm{~mm}$ was used and slid for 10000 cycles for loads between $40 \mathrm{~N}$ and $400 \mathrm{~N}$. For $0.02 \mathrm{~m} / \mathrm{s}$, the simulation was run for 5000 cycles using a contact length of $8 \mathrm{~mm}$ between loads of $600 \mathrm{~N}$ to $1000 \mathrm{~N}$. The contact pressure was solved 5 times throughout the simulation. To account for the reciprocating motion, it is assumed that the material only exceeds the shear-strength in one sliding direction to capture the unidirectional nature of ratch- 


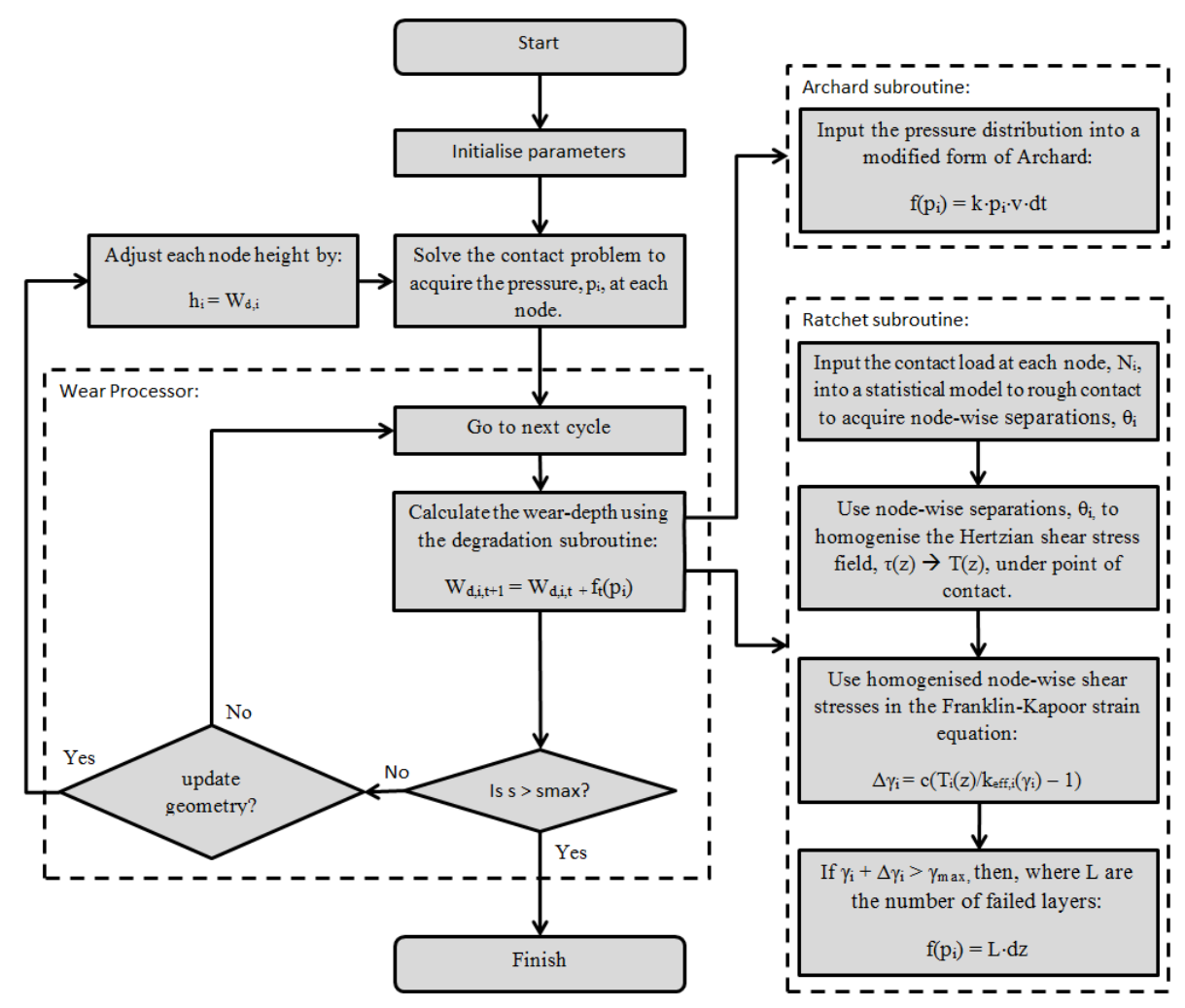

Figure 8: Schematic outlining the wear processor. As we can substitute the degradation for any function, both Archard and Kapoor-Franklin are shown for comparison.

eting preferentially failing in a given direction.

Lastly, a mesh sensitivity analysis was conducted. A simulation of the tribological geometry under a load of $600 \mathrm{~N}$, slid for $100 \mathrm{~m}$, with pin diameter of $8 \mathrm{~mm}$ was used. Each simulation run was performed with a different number of elements at the contact interface, ranging from 10, 25, 50, 100, 200, 400 and 600 elements.

\section{Results}

\subsection{Nano-indentation and micro hardness}

All of the nano-indentation hardness data was observed to follow a decreasing exponential trend from the wear interface of the form:

$$
H=H_{i}+\left(H_{b}-H_{i}\right)\left(1-e^{-b x}\right)
$$

where $H_{i}$ is the hardness close the interface, $H_{b}$ is the bulk hardness, $b$ is the transition rate between interfacial and bulk hardness, and $x$ is the distance from the interface.
Table 1 shows the value of the parameters for each test.

Table 1: Table of the fitting parameter values for hardness and stiffness.

\begin{tabular}{llllll}
\hline $\begin{array}{r}\text { Load } \\
(\mathrm{N})\end{array}$ & $\begin{array}{l}\text { Speed } \\
(\mathrm{m} / \mathrm{s})\end{array}$ & $\begin{array}{l}\mathrm{H}_{b} \\
(\mathrm{GPa})\end{array}$ & $\begin{array}{l}\Delta \mathrm{H} \\
(\mathrm{GPa})\end{array}$ & $\begin{array}{l}\mathrm{H}_{i} \\
(\mathrm{GPa})\end{array}$ & $\mathrm{b}$ \\
\hline 0 & 0 & $5.00 \pm$ & - & - & - \\
40 & 0.05 & $5.00 \pm$ & +0.50 & 5.50 & - \\
240 & & $5.00 \pm$ & +1.29 & 6.29 & - \\
400 & & $6.38 \pm$ & +2.73 & $9.11 \pm$ & 0.048 \\
600 & 0.02 & $6.31 \pm$ & +2.74 & $9.05 \pm$ & 0.013 \\
800 & & $5.89 \pm$ & +2.62 & $8.51 \pm$ & 0.017 \\
1000 & & $5.33 \pm$ & +2.95 & $8.28 \pm$ & 0.016 \\
\hline
\end{tabular}

\subsection{Strain analysis}

The lipping deformation due to tted sliding as observed at the pin edges after experiment can be seen in Figure 9.

Figure 10 shows plots for the strain of the pin after sliding for the variable speed tests, and the 


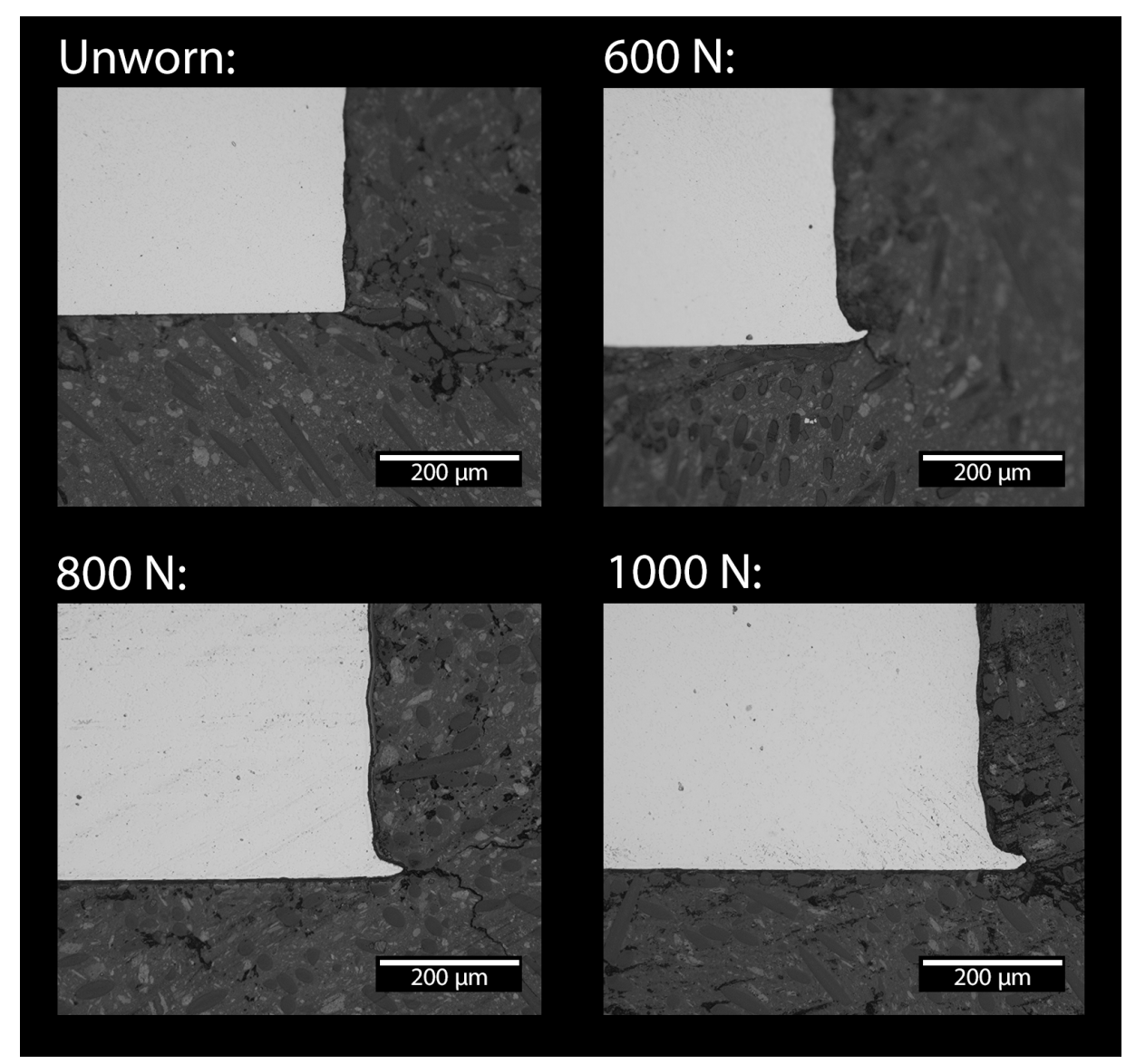

Figure 9: A series of optical micrographs showing the plastic deformation at the edge of the pins for the high load experiments.

high load tests. As it can be seen, the scale of the pin deformation is significantly higher than what is possible in the monotonic tension test. The scale of this deformation is likened to the presence of high hydrostatic pressures (typically $1.5 \mathrm{GPa}$ ) under the point of contact which is known to make brittle materials more ductile [30, 31].

\subsection{Profilometry and pressure analysis}

The statistical distributions of asperity heights for the plate, unworn and worn, can been seen in Figure 11.

\subsection{Finite element model of wear}

The input parameters to the model can be seen in table 2 . The values of $160 \mathrm{~N}, 320 \mathrm{~N}$ and $700 \mathrm{~N}, 900 \mathrm{~N}$ were calculated by interpolating between these values for the high speed and high load tests respectively.

Results from the sensitivity analysis can be seen in Figure 12. The wear-rates have been normalised with respect to the wear-rate value corresponding to a mesh number of 10 . With increasing element number, the value for wear-rate appears to tend to a value of 0.05 .

Wear volume as a function of cycles can be seen in Figure 13. Noticeably, the ratcheting subroutine shows an initial non-linear running-in behaviour, before settling to a linear trend, when compared to Archard. The difference between pin and plate wear, with the pin wearing marginally more than the plate, matches the observed behaviour in experiment, where the plate on average wore less than the pin.

The wear-rate results from the wear simulations, comparing the ratchet and Archard subroutines and the experimental wear-rates respectively, are shown in Figure 14. Importantly, these results demonstrate that for speeds of $0.02 \mathrm{~m} / \mathrm{s}$ to $0.05 \mathrm{~m} / \mathrm{s}$, the ratchet subroutine predicts the correct scale of wear. That is, they all lie within the range of $10^{-15}$ $\mathrm{m}^{3} / \mathrm{Nm}$ to $10^{-13} \mathrm{~m}^{3} / \mathrm{Nm}$. Furthermore, the ratch- 
Table 2: Table of the input parameter values to the finite element model.

\begin{tabular}{lllllllllllll}
\hline $\begin{array}{l}\text { Load } \\
(\mathbf{N})\end{array}$ & $\begin{array}{l}\text { Distance } \\
(\mathbf{m})\end{array}$ & $\begin{array}{l}\text { Speed } \\
(\mathbf{m} / \mathbf{s})\end{array}$ & $\begin{array}{l}\mathbf{E} \\
(\mathbf{G P a})\end{array}$ & $\begin{array}{l}\text { Yield } \\
(\mathbf{M P a})\end{array}$ & $\begin{array}{l}\mathbf{k} \\
(\mathbf{M P a})\end{array}$ & $\mathbf{A}_{c}$ & $\mu$ & $\begin{array}{l}\mathbf{H}_{i} \\
(\mathbf{G P a})\end{array}$ & $\begin{array}{l}\mathbf{H}_{f} \\
(\mathbf{G P a})\end{array}$ & $\begin{array}{l}\mathbf{k}_{\text {eff }} \\
(\mathbf{M P a})\end{array}$ & $\begin{array}{l}\mathbf{c} \\
\left(1 \times 10^{-6}\right)\end{array}$ & stf \\
\hline 40 & 500 & 0.05 & 215 & 450 & 259 & 4740 & 0.55 & 5.0 & 5.50 & 285 & 0.001 & 0.48 \\
240 & & & & & & 3510 & 0.62 & 5.0 & 6.29 & 326 & 7.72 & 1.95 \\
400 & & & & & & 2940 & 0.40 & 5.0 & 9.11 & 473 & 12.8 & 2.15 \\
600 & \multirow{2}{*}{00} & 0.02 & & & & 2640 & 0.38 & 5.0 & 9.05 & 470 & 5.95 & 1.24 \\
800 & & & & & & 2776 & 0.38 & 5.0 & 8.51 & 442 & 13.2 & 2.48 \\
100 & & & & & & 2624 & 0.39 & 5.0 & 8.28 & 430 & 22.5 & 3.73 \\
\hline
\end{tabular}

eting subroutine predicts a difference in the wearrates between the pin and the plate, with the plate wearing slightly less. This behaviour, where the pin wears more than the plate, is often expected in tribological tests [27] due to differences in heat between the mated pairs.

In contrast the wear for the high speed, $0.05 \mathrm{~m} / \mathrm{s}$, case shows a large discrepancy between the magnitudes of wear albeit for the pin only. Likewise, the wear trends do not always agree, with the rate of wear increasing with load in the $0.02 \mathrm{~m} / \mathrm{s}$ case. The reasons for these discrepancies will be discussed later.

The relative error between experiment and simulation can be seen in table 3

Given the deviation of magnitude in the wearrates and wear-volumes in the ratchet subroutine, an optimisation procedure was executed to determine better values of the strain-per-cycle to recreate the wear-rates seen in experiment. This replaces the Tyfour and Kapoor method for strain determination [22]. The results for the strain-rate after using the optimisation procedure are shown in Figure 15. As expected, the strain-rates on both pin and plate are markedly different, with the the pin being strained more per cycle than the plate. The trends in the strain data all appear to be increasing with load, which reflects the increased strain seen in experiment. Additionally, at low loads and speeds, the strain-rate between pin and plate becomes similar perhaps suggesting the differences in strain stem from variations in heat between the mated surfaces.

\section{Discussion}

Most significant of the aforementioned analysis is that the ratcheting subroutine predicts the correct magnitude of wear for $0.02 \mathrm{~m} / \mathrm{s}$ to $0.05 \mathrm{~m} / \mathrm{s}$. The wear-rate magnitude of $1 \times 10^{-14} \mathrm{~m}^{3} / \mathrm{Nm}$ is typical for co-cr $[32,10,14]$. This is important because the magnitude of wear-rates has essentially been determined through a mechanistic approach, which accounts for wear depth based on how much the material can strain before it ruptures to create a wear particle.

Regarding the sensitivity analysis, the wear-rates in the simulation appear to increase with decreasing element size or increasing element number at the wear interface and converges around 600 elements within the wear-interface. Reasons for this convergence in wear-rate can be attributed to the fact that with decreasing element size, the amount of force carried at a node, as well as the number of asperities at that node, fall to 0 . In order to maintain the same level of pressure, the real area of contact also decreases until a true value of stress and therefore wear-rate, which is controlled by this stress, is reached.

Unlike the Archard case, the ratcheting case demonstrates a wear-in period, as shown in Figure 13. Initially, the rate of wear is not very high, due to the material starting at $0 \%$ initial strain. However, after a couple of cycles, the material begins to wear after which the apparent area becomes more rough. This roughness causes greater concentrations of pressure which accelerate the wear process. However, after a couple thousand cycles, the material appears to reach a steady-state after which is the wear loss with distance becomes linear.

Importantly, the benefits of this modelling approach allows one to observe how wear is affected by changes in material properties and evolutions in the surface roughness.

It is important to stress that this modelling approach only has a range of validity where ratcheting wear operates as the primary wear mechanism. For the low load $40 \mathrm{~N}$ simulation, the wear spiked considerably. This is expected, however, under these loads the primary wear mechanism was either oxidative or fatigue driven and is presently 
Table 3: Relative errors between experiment and simulation.

\begin{tabular}{|c|c|c|c|c|c|c|c|c|}
\hline \multirow[t]{2}{*}{$\begin{array}{c}\text { Load } \\
(\mathrm{N})\end{array}$} & \multirow[t]{2}{*}{$\begin{array}{l}\text { Velocity } \\
(\mathrm{m} / \mathrm{s})\end{array}$} & \multirow[t]{2}{*}{$\begin{array}{l}\text { Distance } \\
\quad(\mathbf{m})\end{array}$} & \multicolumn{2}{|c|}{$\begin{array}{l}\text { Experimental wear-rate } \\
\left(\mathbf{m}^{3} / \mathbf{N m}\right) \times \mathbf{1 0}^{-14}\end{array}$} & \multicolumn{2}{|c|}{$\begin{array}{l}\text { Simulation wear-rate } \\
\left(\mathbf{m}^{3} / \mathbf{N m}\right) \times \mathbf{1 0}^{-14}\end{array}$} & \multicolumn{2}{|c|}{$\begin{array}{c}\text { Relative Error } \\
(\%)\end{array}$} \\
\hline & & & Pin & Plate & Pin & Plate & Pin & Plate \\
\hline 40 & 0.05 & 500 & 0.70 & 1.00 & - & - & - & - \\
\hline 240 & & & 0.80 & 0.25 & 1.48 & 1.32 & 85.3 & 550 \\
\hline 400 & & & 1.15 & 0.82 & 1.89 & 1.78 & 64.4 & 122 \\
\hline 600 & 0.02 & 100 & 1.82 & 0.60 & 1.31 & 1.19 & 27.9 & 97.5 \\
\hline 800 & & & 1.51 & 0.48 & 1.14 & 1.05 & 24.3 & 119 \\
\hline 1000 & & & 1.42 & 0.50 & 1.34 & 1.27 & 5.51 & 154 \\
\hline
\end{tabular}

not accounted for in the model, leading to an overprediction in the wear-rate. Furthermore, the current model does not account for the reversal of strain due to reciprocated sliding motion, which if accounted for could improve the predictability of the model.

Differences in the wear-rate between pin and plate are also to some degree captured by the model. This is due to the entire interface of the pin being strained at all times through the simulation, while the plate only strains when material passes over it. However, the scale of difference in the model is markedly under-predictive. This may be due to the fact the strain-rates for the model are calculated only from the pin, rather than both pin and plate. Differences in pin and plate strain-rates can be explained in terms of frictional heating dissipation. The pin experiences more heat over the duration of the test and as such leads to a greater degree of wear on the pin. These differences could be remedied with more detail shear strain analysis, including the strain to failure under shear, for both pin and plate.

Differences in the strain-rates, after the optimisation routine as shown in Figure 15, may be explained by a variety of physical phenomena not yet accounted for in the analysis. The higher strainrate of the pin would likely be a consequence of the pin seeing more frictional heat throughout the analysis. Incorporation of such analysis has been done by Franklin [21] in their block model, and showed a marked increase in wear with sliding speed. It is likely that, by incorporating changes in material properties with heat, the $0.05 \mathrm{~m} / \mathrm{s}$ simulation will showcase more appropriate wear-rates.

The optimised values suggest that the pin should strain much higher than the plate. The highest relative error for the pin is $41 \%$, corresponding to the $240 \mathrm{~N}, 0.05 \mathrm{~m} / \mathrm{s}$, simulation whereas the plate reaches as high at $71 \%$ in some cases. It is not unexpected that the pin would strain more than the plate due to the pin dispersing more energy as a result of it always being under loaded sliding. Another likelihood is that the plate retains wear debris much better than the pin, where interfacial material is often strained to and then fractured from the pin edge $[8,9]$. The discrepancy between experiment and simulation could then be improved by better strain measurement techniques for both pin and plate.

Interestingly, the wear-rate results show a dependency on the probability distribution function of asperity heights with the wear-rate. For $0.05 \mathrm{~m} / \mathrm{s}$ at $40 \mathrm{~N}$, the wear-rate spikes where the distribution function is itself has a higher more narrow peak. The distribution function also appears to spread out with load, leading the wear-rate to drop correspondingly in the $0.05 \mathrm{~m} / \mathrm{s}$ test. However, this same behaviour is not reflected in the $0.02 \mathrm{~m} / \mathrm{s}$ results. This is likely due to the reduction in hardness with loads above $600 \mathrm{~N}$, counter-acting the spread of asperity heights. This further highlights the ability for this model to capture several competing factors and their influence on the wear-rate, and could lead to further studies that help delineate the sensitivity of these parameters on the wear process.

This modelling approach may be further improved by incorporating changes in surface roughness, and changes in material properties in response to frictional heating.

\section{Conclusions}

A finite element model of wear, not based on the Archard wear equation, has been given. Primarily, one that is designed to capture a ratcheting wear 
(a)

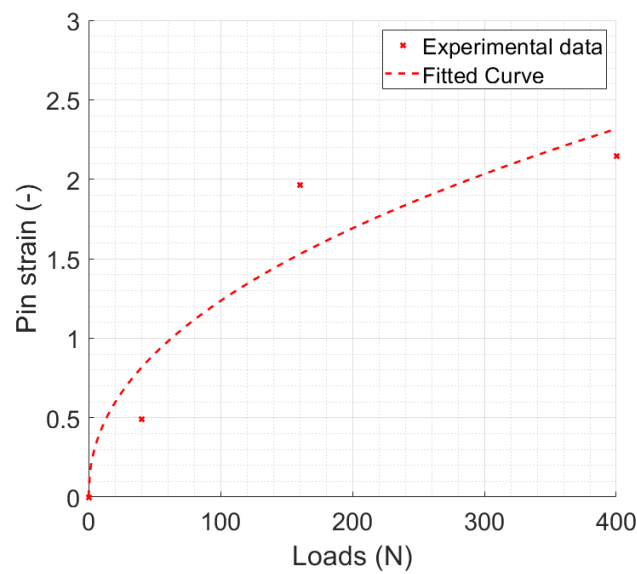

(b)

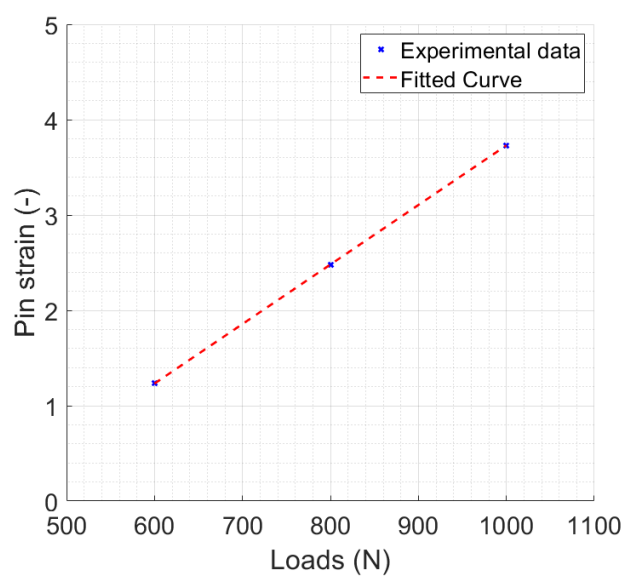

Figure 10: (a) Load vs strain graph for the worn pins for the variable speed test, and (b) the high load test.

process. The benefits of this approach, which are not afforded by Archard, due to its mechanistic nature are thus:

- Surface roughness can be incorporated into the analysis.

- Influences of changes in material properties, particularly work-hardening effects, on wearrates can be captured.

- Different types of microscale heterogeneity could be implemented into the analysis, allowing one to better optimise the system in response to sliding wear.

- Coatings or wear-reducing oxides may easily be implemented into the analysis by modifying the Hertzian contact stress equations to include the influence of a surface layer with different material properties. (a)

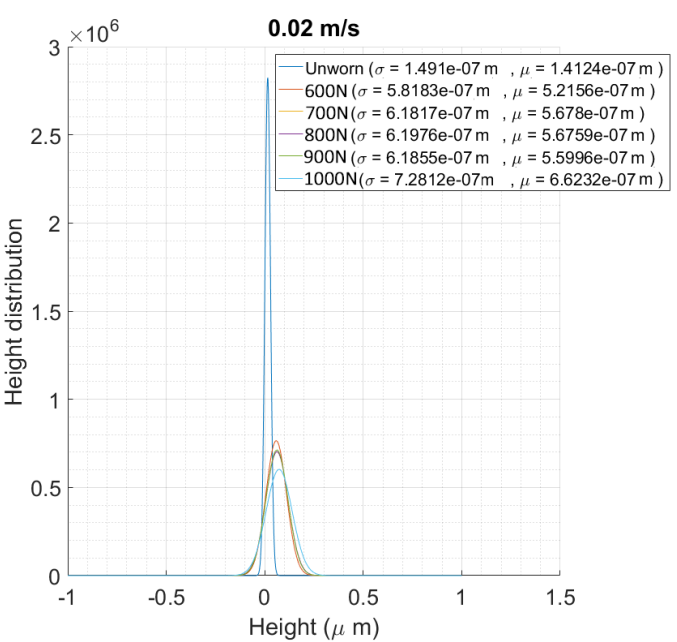

(b)

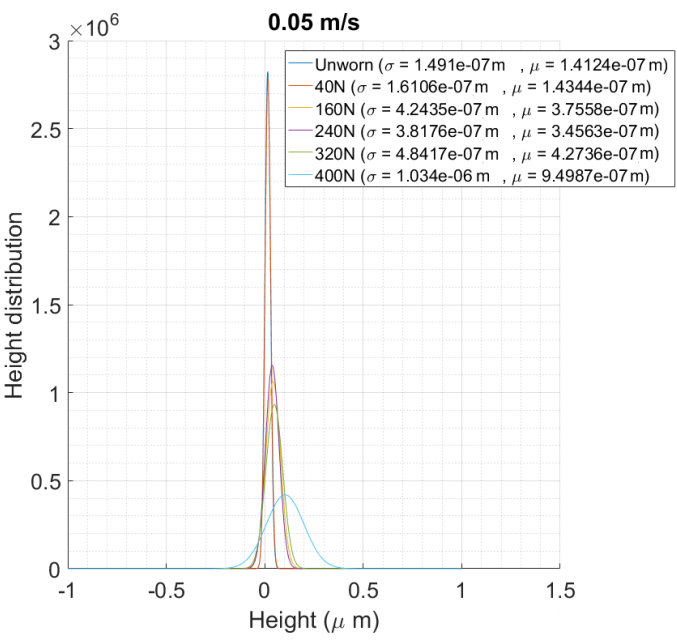

Figure 11: Statistical distributions of asperity heights for the sliding wear tests.

As a result, this wear model affords a much greater range of predictability than would be possible with Archard. The specific wear rate used in the Archard wear equation has no clear physical interpretation. The mechanistic approach of the ratcheting sub-routine allows one to see how wear changes due to environmental changes in mechanical properties, microscale heterogeneity, or coatings. However, it must be stressed that this wear model is only valid under conditions in which ratcheting wear occurs.

While the model is capable of capturing the correct scale of wear, discrepancies in the trends may be owed to the fact that the present model does not yet account a variety of phenomena such as the evolution in the surface roughness. Presently, only 


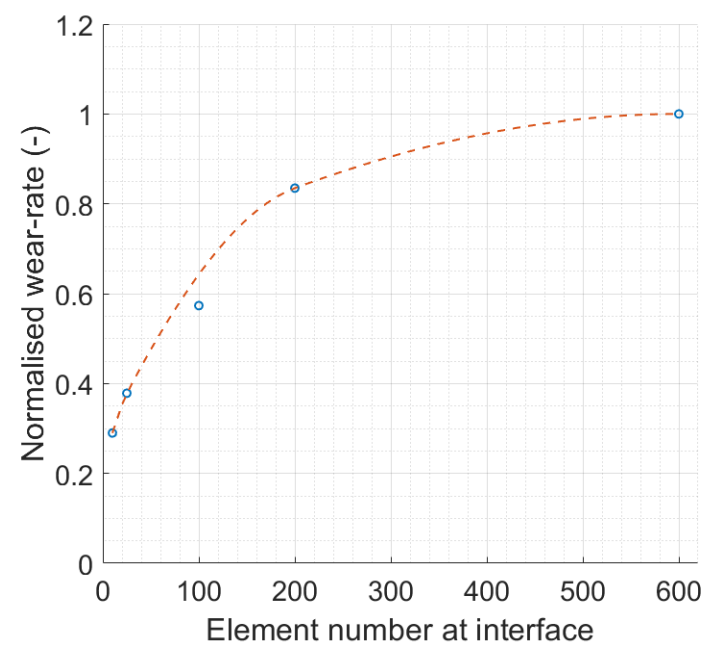

Figure 12: Mesh sensitivity analysis for a $600 \mathrm{~N}$ test run for $100 \mathrm{~m}$ on a geometry with pin diameter $8 \mathrm{~mm}$. The wearrate values have been normalised against the wear-rate value corresponding to a mesh number of 10 at the wear interface.

the surface roughness after wear is used. Evolution of material properties through frictional heating and the presence of microscale heterogeneity such as void imperfections are also not accounted for. Additionally, the strain equation of Dautzenberg [25] does not account for strains produced under cyclic motion and leads to an over-prediction in shear strain-per-cycle.

\section{Acknowledgements}

The author would like to thank Rolls-Royce, plc. and the EPSRC for the funding of this project.

\section{Appendix}

\subsection{Derivation of the force function}

The derive the equation for the pressure between two cylinders under contact as a function of displacement, the RHS of the equation for two cylinders in contact [16] was plotted in Matlab on the $\mathrm{y}$-axis and the LHS on the $\mathrm{x}$-axis. This was done so that the plot was expressed in terms of the inverse solution. This analytical equation is:

$$
\frac{\delta}{R}=\left(\frac{p_{0}}{E^{*}}\right)^{2}\left[2 \ln \left(\frac{4 E^{*}}{p_{0}}\right)-1\right]
$$

where $\delta$ is the interference or penetration between the contacting bodies, $R$ is the radius, $p_{0}$ is the maximum pressure. (a)

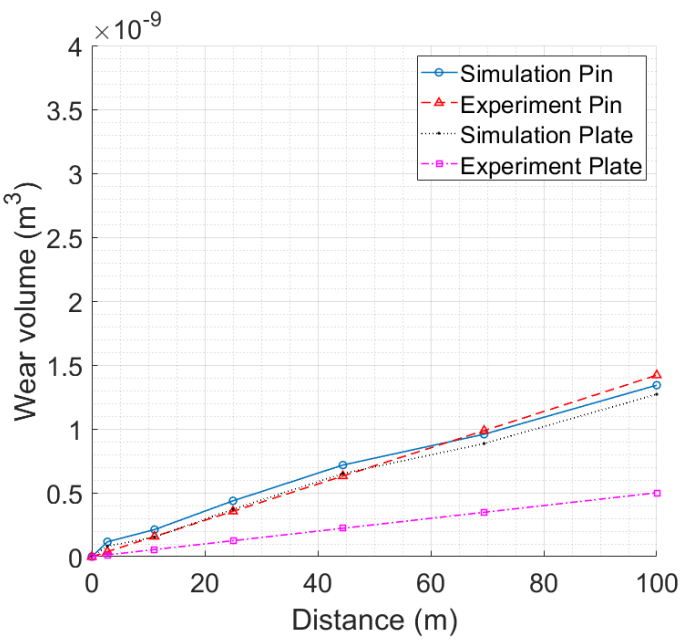

(b)

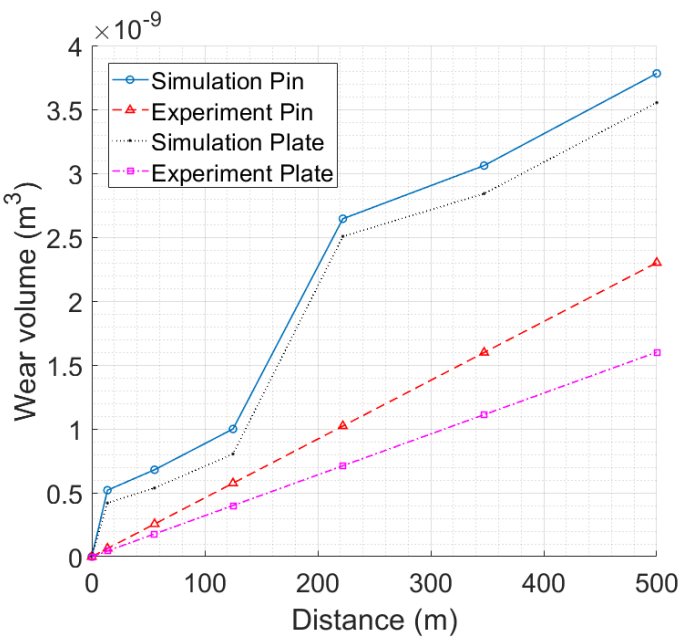

Figure 13: Wear volume versus sliding distance for the wear simulation comparing the Archard subroutine to the Ratcheting subroutine for (a) $0.02 \mathrm{~m} / \mathrm{s}$ and (b) $0.05 \mathrm{~m} / \mathrm{s}$.

A function of the form $f=a x^{b}$ was fitted to the analytical solution as this appeared to give a reasonable fit, where $x=\delta / R$ and $f=p_{0} / E^{*}$. The fitting range was $0 \leq p_{0} \leq 5 \times 10^{10} \mathrm{~Pa}$. The reason for this chosen pressure range is that, at values above this, the logarithmic term in the equation causes the analytic solution to deviate from the fitting function form, thus the fitted form only has this range of validity. Nevertheless, provided the maximum pressure values are within this range (which they often are) then the function gives a reasonable fit. The fitting results were:

$$
p_{0} \simeq 0.56 E^{*}\left(\frac{\delta}{R}\right)^{0.64}
$$

With this equation, it is now possible to express 
(a)

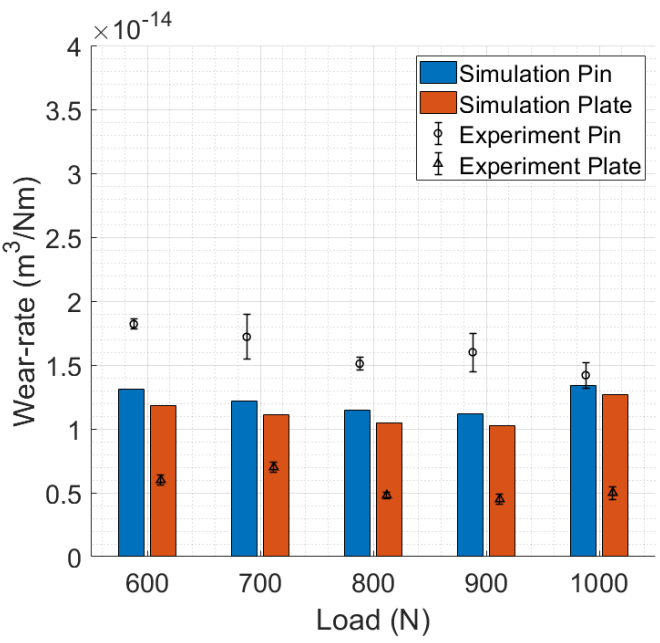

(b)

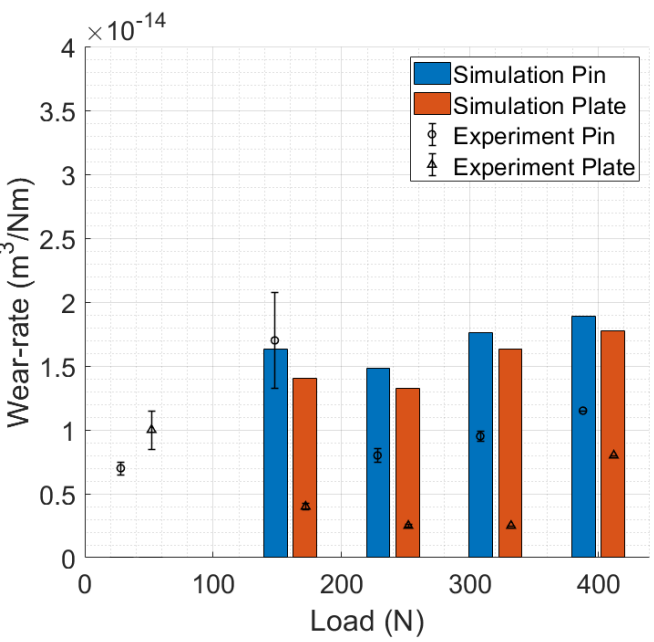

Figure 14: Wear-rates versus load of the simulation with the ratchet subroutine compared to the Archard routine for (a) $0.02 \mathrm{~m} / \mathrm{s}$ and $(\mathrm{b}) 0.05 \mathrm{~m} / \mathrm{s}$.

the contact force resulting from a desired interference, as well as the radius of contact, by using the equations for cylindrical contact force, $F$, and area, $a$, from Johnson [33]:

$$
\begin{gathered}
F / L=\frac{\pi R}{E^{*}} p_{0}{ }^{2} \\
a / L=2\left(\frac{4 F R}{\pi E^{*}}\right)^{0.5}
\end{gathered}
$$

Substituting equation 18 into equation 19 , and expanding out the squared term, gives:

$$
F / L \simeq \pi R E^{*} 0.31\left(\frac{\delta}{R}\right)^{1.28}
$$

(a)

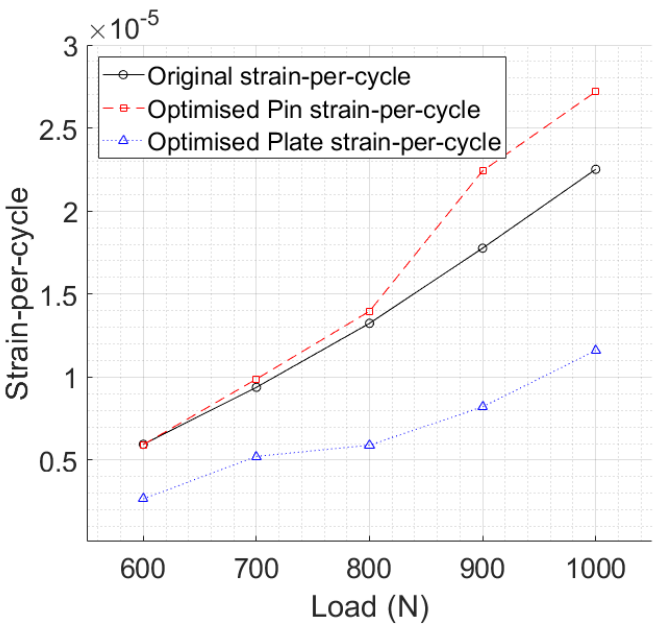

(b)

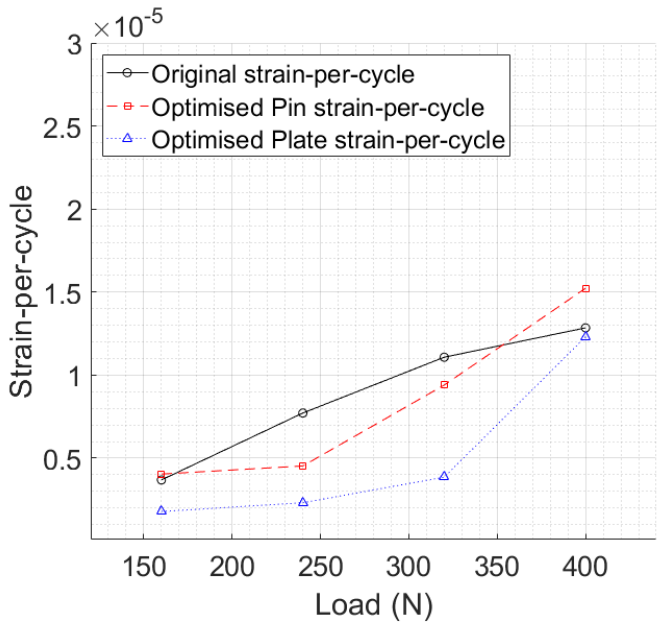

Figure 15: Comparison between the shear strain-per-cycle calculated from the worn pin and the strains determined from an optimisation routine for (a) $0.02 \mathrm{~m} / \mathrm{s}$ and (b) 0.05 $\mathrm{m} / \mathrm{s}$.

\section{References}

[1] P. Crook, Cobalt-base alloys resist wear, corrosion, and heat, Advanced Materials \& Processes 145 (4) (1994) 27-30.

[2] K. F. Dufrane, H. Ocken, Measurements of wear in nuclear-components, Wear 101 (1) (1985) 13-31.

[3] H. Ocken, Reducing the cobalt inventory in light waterreactors, Nuclear Technology 68 (1) (1985) 18-28.

[4] J. K. Kim, S. J. Kim, The temperature dependence of the wear resistance of iron-base norem 02 hardfacing alloy, Wear 237 (2) (2000) 217-222.

[5] J. L. Sulley, I. Hookham, B. Burdett, K. Bridger, Introduction of hot isostatically pressed, reactor coolant system components in pwr plant, Proceedings of the 18th International Conference on Nuclear Engineering 2010, Vol 5 (2011) 357-367.

[6] J. F. Archard, Contact and rubbing of flat surfaces, Journal of Applied Physics 24 (8) (1953) 981.

[7] M. A. Ashraf, R. Ahmed, O. Ali, N. H. Faisal, A. M. 
El-Sherik, M. F. A. Goosen, Finite element modeling of sliding wear in a composite alloy using a free-mesh, Journal of Tribology-Transactions of the Asme 137 (3) (2015).

[8] P. Cross, G. Limbert, D. Stewart, R. Wood, Ratcheting wear of a cobalt-chromium alloy during reciprocated self-mated dry sliding, Wear 426-427 (2019) 1142 - 1151, 22nd International Conference on Wear of Materials.

[9] D. H. E. Persson, On the mechanisms behind the tribological performance of stellites, Thesis, uppsala University (2005).

[10] A. Frenk, W. Kurz, Microstructural effects on the sliding wear-resistance of a cobalt-based alloy, Wear 174 (12) (1994) 81-91.

[11] H. Yu, R. Ahmed, H. D. Lovelock, S. Davies, Influence of manufacturing process and alloying element content on the tribomechanical properties of cobalt-based alloys, Journal of Tribology-Transactions of the Asme 131 (1) (2009).

[12] W. Tyfour, J. Beynon, A. Kapoor, The steady state wear behaviour of pearlitic rail steel under dry rollingsliding contact conditions, Wear 180 (1) (1995) $79-89$.

[13] K. Johnson, Contact mechanics and the wear of metals, Wear 190 (2) (1995) 162 - 170. doi:https://doi.org/10.1016/0043-1648(95)066659. URL http: //www.sciencedirect.com/science/article/pii/0043164895066659

[14] E. Cabrol, C. Boher, V. Vidal, F. Rezai-Aria, F. Touratier, Plastic strain of cobalt-based hardfacings under friction loading, Wear 330 (2015) 354-363.

[15] A. Kapoor, Wear by plastic ratchetting, Wear 212 (1) (1997) $119-130$.

[16] A. Kapoor, J. Williams, K. Johnson, The steady state sliding of rough surfaces, Wear 175 (1) (1994) 81 - 92.

[17] M. J. Zehetbauer, H. P. Stüwe, A. Vorhauer, E. Schafler, J. Kohout, The Role of Hydrostatic Pressure in Severe Plastic Deformation, 2005, pp. 433-446.

[18] D. Persson, S. Jacobson, S. Hogmark, The influence of phase transformations and oxidation on the galling resistance and low friction behaviour of a laser processed co-based alloy, Wear 254 (11) (2003) 1134 - 1140.

[19] S. Jacobson, S. Hogmark, Surface modifications in tribological contacts, Wear 266 (3) (2009) $370-378$.

[20] A. Kapoor, F. Franklin, Tribological layers and the wear of ductile materials, Wear 245 (1) (2000) $204-215$.

[21] F. J. FRANKLIN, T. CHUNG, A. KAPOOR, Ratcheting and fatigue-led wear in rail-wheel contact, Fatigue \& Fracture of Engineering Materials \& Structures 26 (10) (2003) 949-955.

[22] W. Tyfour, J. Beynon, A. Kapoor, Deterioration of rolling contact fatigue life of pearlitic rail steel due to dry-wet rolling-sliding line contact, Wear 197 (1) (1996) $255-265$.

[23] E. Voce, The relationship between stress and strain for homogeneous deformations, J Inst Metals 74 (1948) 537-562.

[24] D. H. E. Persson, S. Jacobson, S. Hogmark, Investigation of anti-galling and low friction properties of laser processed co-based materials, International Congress on Applications of Lasers \& Electro-Optics (2001) 685693.

[25] J. Dautzenberg, J. Zaat, Quantitative determination of deformation by sliding wear, Wear 23 (1) (1973) 9-19.

[26] A. Kapoor, A re-evaluation of the life to rupture of duc- tile metals by cyclic plastic strain, Fatigue \& Fracture of Engineering Materials \& Structures 17 (2) (1994) 201219 .

[27] J. Williams, Engineering Tribology, Cambridge University Press, 1994, Ch. 5.

[28] K. L. Johnson, Contact Mechanics, Cambridge University Press, 1985, cambridge Books Online. URL http://dx.doi.org/10.1017/CB09781139171731

[29] V. Hegadekatte, N. Huber, O. Kraft, Finite element based simulation of dry sliding wear, Modelling and Simulation in Materials Science and Engineering 13 (1) (2005) 57-75.

[30] F. P. Bullen, F. Henderson, H. L. Wain, M. S. Paterson, The effect of hydrostatic pressure on brittleness in chromium, The Philosophical Magazine: A Journal of Theoretical Experimental and Applied Physics 9 (101) (1963) 803-815.

[31] M. Yajima, M. Ishii, M. Kobayashi, The effects of hydrostatic pressure on the ductility of metals and alloys, International Journal of Fracture 6 (2) (1970) 139-150.

[32] H. So, C. T. Chen, Y. A. Chen, Wear behaviours of laser-clad stellite alloy 6, Wear 192 (1-2) (1996) 78-84.

[33] K. L. Johnson, The strength of surfaces in rolling contact, Proceedings of the Institution of Mechanical Engineers, Part C: Mechanical Engineering Science 203 (3) (1989) 151-163. 